\title{
Do statins influence platelet reactivity on acetylsalicylic acid therapy in patients with type 2 diabetes?
}

Marek Postula, 2*, Marek Rosiak ${ }^{1 *}$, Agnieszka Kaplon-Cieslicka ${ }^{1}$, Agnieszka Kondracka ${ }^{3}$, Ewa Trzepla ${ }^{4}$, Krzysztof J. Filipiak ${ }^{1}$, Andrzej Czlonkowski², Grzegorz Opolski ${ }^{1}$

${ }^{1}$ Department of Cardiology, Medical University of Warsaw, Warsaw, Poland

${ }^{2}$ Department of Experimental and Clinical Pharmacology,

Medical University of Warsaw, Warsaw, Poland

${ }^{3}$ Department of Internal Medicine and Endocrinology,

Medical University of Warsaw, Warsaw, Poland

${ }^{4}$ Medical Center, Medical University of Warsaw, Warsaw, Poland

\begin{abstract}
Background: Type 2 diabetes (T2DM) patients are at increased risk of cardiovascular events despite long-term acetylsalicylic acid (ASA) therapy. This study was performed to establish the prevalence of high platelet reactivity (HPR) on ASA in T2DM and to identify its predictors.
\end{abstract}

Methods: The study included 185 T2DM on chronic ASA therapy and to assess platelet reactivity during long-term ASA therapy, we applied the point-of-care method VerifyNow ${ }^{\circledR}$ aspirin test (Accumetrics, San Diego, CA, USA).

Results: Compared with the low platelet reactivity (LPR) group, patients with HPR had higher triglyceride levels (145 vs. $118 \mathrm{mg} / \mathrm{dL}, p=0.041$ ), were less frequently treated with statins $(57.1 \%$ vs. $75.3 \% ; p=0.038)$ and tumor necrosis factor-alpha $(T N F-\alpha)$ concentrations were higher (2.15 vs. $1.74 \mathrm{pg} / \mathrm{mL} ; p=0.052)$. In a multivariate analysis only statin therapy (OR 0.375; 95\% CI 0.15-0.91; $p=0.030)$ and lower concentrations of TNF- $\alpha$ (for each $1.0 \mathrm{pg} / \mathrm{mL}$ : OR 1.3; $95 \%$ CI 1.00-1.72; $p=0.046)$ were predictive of LPR.

Conclusions: Our study provides indirect evidence that the beneficial effect of statins on platelet activity may be related to their non-lipid-mediated, pleiotropic mechanisms of action. This might have been partly related to decreased platelet reactivity in patients receiving statin therapy. In our study in patients with T2DM, platelet reactivity on ASA therapy measured with VerifyNow ${ }^{\circledR}$ was associated with TNF- $\alpha$ concentrations and statin therapy. These results may imply a role for subclinical systemic inflammation and a beneficial effect of statins in the development of HPR in T2DM. (Cardiol J 2012; 19, 5: 494-500)

Key words: acetylsalicylic acid, platelet reactivity, statins, tumor necrosis factor-alpha, coronary artery disease

Address for correspondence: Marek Rosiak, MD, PhD, Department of Cardiology, Medical University of Warsaw, ul. Banacha 1a, 02-097 Warszawa, Poland, tel: +48 59929 58, fax: + 48599 19 57, e-mail: marek.rosiak@gmail.com *These authors contributed to this work equally.

Received: 01.05.2012 Accepted: 12.06.2012 


\section{Introduction}

Type 2 diabetes (T2DM) is associated with progressive atherosclerosis and represents a major cause of cardiovascular morbidity and mortality in developed countries [1]. Despite well-documented benefits, acetylsalicylic acid (ASA) treatment does not provide complete protection against cardiovascular (CV) events. Decreased response to antiplatelet agents, defined as an inadequate inhibition of platelet activation and aggregation when assessed in vitro, constitutes an emerging problem in CV pharmacotherapy. Thus, in view of the possible clinical consequences of high platelet reactivity in patients on ASA therapy, a better understanding of its etiology and accurate identification of its risk factors seems of particular importance for optimizing treatment in patients at high CV risk. Increased platelet activity has been also reported in insulin-resistant patients on ASA therapy. In the diabetic population, factors related to ASA low-responsiveness have been reported to include prior $\mathrm{CV}$ disease, obesity, poor glycemic control, insulin resistance, total, LDL- and HDL-cholesterol concentrations, triglyceride concentrations, and microalbuminuria [2-7]. In order to assess platelet reactivity in patients with T2DM on long-term ASA therapy, we applied the point-of-care method approved by US Food and Drug Administration VerifyNow $^{\circledast}$ aspirin test (Accumetrics, San Diego, CA, USA) to quantify platelet reactivity. Recent data showed that VerifyNow ${ }^{\circledR}$ assay measurements demonstrate the lowest day-to-day variation and the highest repeatability during ASA therapy among other platelet function tests [8].

The objective of this study was, therefore, to evaluate the prevalence of high platelet reactivity (HPR) on ASA therapy in patients with T2DM and to identify clinical and biochemical variables that may be predisposed to a decreased response to lowdose ASA.

\section{Methods}

The study consists of preliminary, exploratory analysis of the AVOCADO trial (Aspirin Vs/Or Clopidogrel in Aspirin-resistant Diabetics inflammation Outcomes Study) results, a multi-center, prospective, randomized, open-label study. The study subjects were recruited consecutively from patients with T2DM presenting to the outpatient clinic of the Central Teaching Hospital of the Medical University of Warsaw. The local ethics committee of the Medical University of Warsaw approved both the study protocol and the informed consent form. The study was conducted in accordance with the current version of the Declaration of Helsinki at the time when the study was designed.

Between January 2007 and October 2008, 642 patients were screened for eligibility. The full characterization of the study inclusion and exclusion criteria were published previously [9]. Briefly, 185 patients with T2DM were recruited who, at the time of enrollment, had been taking ASA tablets at the dose of $75 \mathrm{mg}$ per day for at least 3 months for primary or secondary prevention of myocardial infarction. No clopidogrel or antiplatelet drugs other than ASA were used in any of the investigated patients. All patients had been taking oral antidiabetic agents and/or insulin for at least 6 months; diet-controlled diabetic patients were not included. Compliance to ASA therapy was determined at the study entry based upon the patient's own statements and serum thromboxane B2 (S-TxB2) level measurement.

\section{Blood sample and assay procedures}

Blood samples were taken in the morning $2-3 \mathrm{~h}$ after the last ASA dose. Whole blood for S-TxB2 was allowed to clot at $37^{\circ} \mathrm{C}$ for $1 \mathrm{~h}$ before separating serum by centrifugation. Regular laboratory testing was performed using standard techniques and included complete blood cell and platelet counts, fasting glycemia, glycosylated hemoglobin, lipid profile, C-reactive protein (CRP) and serum creatinine concentrations. Serum tumor necrosis factor-alpha (TNF- $\alpha$ ) concentration was quantified using a commercially available enzyme immunoassay: hsTNF- $\alpha$ human (R \& D Systems, Abingdon, UK) according to the manufacturer's instructions. Assays were performed in duplicate in batches. S-TxB2 was measured also with an enzyme immunoassay kit according to the manufacturer's instructions (Cayman Chemicals, Ann Arbor, MI, USA). Samples with results outside the standard curve were re-assayed with appropriate dilutions. An optimal compliance was confirmed by S-TxB2 levels below $7.2 \mathrm{ng} / \mathrm{mL}$ in all patients as described previously in a diabetic population [6,9]. Of 185 patients with T2DM, a subgroups of subjects with high platelet reactivity (HPR) and low platelet reactivity (LPR) were selected on the basis of the results of the VerifyNow ${ }^{\circledast}$ Aspirin Assay system (Accumetrics Inc, San Diego, CA).

\section{Platelet function analysis}

VerifyNow. VerifyNow ${ }^{\circledR}$ Aspirin Assay (Accumetrics, San Diego, CA, USA) is a point-of-care 
Table 1. Important variables impacting on acetylsalicylic acid resistance in a simple logistic regression model.

\begin{tabular}{|c|c|c|c|}
\hline Variable & OR & $95 \% \mathrm{Cl}$ & $\mathbf{P}$ \\
\hline Gender & 1.14 & $0.54-2.38$ & 0.729 \\
\hline Age [years] & 0.82 & $0.54-1.26$ & 0.374 \\
\hline Total cholesterol & 1.54 & $0.85-1.57$ & 0.359 \\
\hline LDL-cholesterol & 1.17 & $0.92-1.47$ & 0.191 \\
\hline HDL-cholesterol & 1.41 & $0.57-3.50$ & 0.453 \\
\hline Triglycerides & 1.13 & $0.98-1.29$ & 0.093 \\
\hline TNF- $\alpha$ & 1.31 & $1.01-1.70$ & 0.040 \\
\hline hsCRP & 0.89 & $0.71-1.11$ & 0.303 \\
\hline Body mass index & 0.86 & $0.59-1.26$ & 0.446 \\
\hline Waist to hip ratio & 0.90 & $0.60-1.35$ & 0.602 \\
\hline Systolic blood pressure & 0.90 & $0.74-1.10$ & 0.305 \\
\hline Diastolic blood pressure & 0.88 & $0.64-1.20$ & 0.408 \\
\hline Heart rate & 0.75 & $0.51-1.11$ & 0.150 \\
\hline Current smoking & 1.20 & $0.37-3.87$ & 0.760 \\
\hline Fasting glucose & 1.05 & $0.92-1.20$ & 0.440 \\
\hline $\mathrm{HbA}_{1 \mathrm{c}}$ & 1.05 & $0.80-1.41$ & 0.717 \\
\hline Hemoglobin & 1.21 & $0.92-1.60$ & 0.170 \\
\hline Red blood cells & 1.13 & $0.75-1.70$ & 0.563 \\
\hline White blood cells & 1.00 & $0.83-1.21$ & 0.984 \\
\hline Platelet count & 0.98 & $0.72-1.34$ & 0.919 \\
\hline Mean platelet volume & 1.02 & $0.74-1.40$ & 0.923 \\
\hline Fibrinogen & 0.89 & $0.63-1.25$ & 0.495 \\
\hline Serum creatinine & 1.02 & $0.91-1.14$ & 0.702 \\
\hline eGFR & 0.83 & $0.57-1.21$ & 0.328 \\
\hline Statins & 0.44 & $0.20-0.94$ & 0.034 \\
\hline Fibrates & 0.79 & $0.25-2.48$ & 0.689 \\
\hline Metformin & 1.53 & $0.69-3.42$ & 0.298 \\
\hline Sulphonylurea derivatives & 0.64 & $0.30-1.36$ & 0.248 \\
\hline Insulin & 1.11 & $0.51-2.41$ & 0.795 \\
\hline ACE-inhibitors & 0.61 & $0.29-1.29$ & 0.196 \\
\hline Beta-blockers & 1.30 & $0.55-2.94$ & 0.564 \\
\hline Calcium channel blockers & 1.73 & $0.82-3.66$ & 0.148 \\
\hline Nitrates & 0.41 & $0.05-3.33$ & 0.405 \\
\hline Proton pump inhibitors & 0.98 & $0.95-1.11$ & 0.696 \\
\hline
\end{tabular}

OR — odds ratio; $\mathrm{Cl}$ - confidence interval; $\mathrm{LDL}$ - low density lipoprotein; HDL - high density lipoprotein; TNF- $\alpha$ - tumor necrosis factor-alpha; hsCRP - high-sensitivity C-reactive protein;

$\mathrm{HbA}_{1 \mathrm{c}}$ - glycosylated hemoglobin; eGFR - estimated glomerular

filtration rate; $\mathrm{ACE}$ - angiotensin-converting enzyme

system that uses cartridges containing a lyophilized preparation of human fibrinogen-coated beads, arachidonic acid, preservative and buffer. When aggregation occurs, the system converts luminosity transmittance units into ASA reaction units (ARU) for VerifyNow ${ }^{\circledR}$. According to the manufacturer, ARU $\geq 550$ indicates no effect of ASA on platelet aggregation, whereas ARU $<550$ indicates platelet dysfunction due to ASA [8, 9].
Table 2. Important variables impacting on high on acetylsalicylic acid platelet reactivity in a multiple logistic regression model.

\begin{tabular}{lccc}
\hline Variable & OR & $95 \% \mathbf{C l}$ & P \\
\hline Total cholesterol & $0.847^{*}$ & $0.45-1.60$ & 0.608 \\
Statins & $1.248^{* *}$ & $0.96-1.63$ & 0.103 \\
Triglycerides & $1.147 \dagger$ & $1.00-1.31$ & $\mathbf{0 . 0 4 6}$ \\
TNF- $\alpha$ & $0.790 \ddagger$ & $0.60-1.04$ & 0.088 \\
hsCRP & 0.375 & $0.15-0.91$ & $\mathbf{0 . 0 3 0}$ \\
\hline
\end{tabular}

*Odds ratio (OR) for each $50 \mathrm{mg} / \mathrm{dL}$ total cholesterol increment; **OR for each $50 \mathrm{mg} / \mathrm{dL}$ triglycerides increment; †OR for each $0.5 \mathrm{pg} / \mathrm{mL}$ TNF- $\alpha$ increment; $\neq$ OR for each $2.0 \mathrm{mg} / \mathrm{dL}$ hsCRP increment; $\mathrm{Cl}$ - confidence interval; TNF- $\alpha$ - tumor necrosis factor-alpha; hsCRP — high-sensitivity C-reactive protein

\section{Statistical analysis}

Normally distributed continuous variables are presented as means \pm standard deviation (SD), whereas variables with a highly skewed distribution are presented as medians (interquartile ranges). Categorical variables are presented as frequencies (percentages). Normality of distribution was assessed using graphical methods. Differences between HPR and LPR group were analyzed using Student's $t$-test, the Mann-Whitney U-test, the $\chi^{2}$ or Fisher's exact test, as appropriate.

Selected variables were checked for associations with HPR using a univariate logistic regression model. The final multivariate model was derived using the Akaike information criterion. The results are presented as odds ratios (OR) with their 95\% confidence intervals (CI). All statistical tests were performed at significance level $\alpha=0.05$ (twosided). Univariate and multivariate analyses of predictors for HPR are shown in Tables 1 and 2. The reported analysis is exploratory and therefore no formal a priori power analysis was performed.

\section{Results}

A total of 185 subjects with T2DM were enrolled and their results analyzed. Mean \pm SD demographic data, concurrent medications and biochemical and hematological parameters for the study population are presented in Tables $3-5$. Inadequate platelet inhibition defined as HPR with $75 \mathrm{mg}$ ASA daily was detected in 35 (18.92\%) patients. Patient characteristics were similar among patients with LPR and HPR patients for all pertinent demographic and clinical data (Tables 3-5). Of the biochemical and hematological parameters evaluated, patients with HPR had higher triglyceride levels (145 vs. $118 \mathrm{mg} / \mathrm{dL}, \mathrm{p}=0.041$ ) and higher 
Table 3. Demographics data.

\begin{tabular}{lccc}
\hline Characteristics & LPR $(\mathbf{n}=\mathbf{1 5 0})$ & HPR $(\mathbf{n}=35)$ & P \\
\hline Age [years] & $66.7 \pm 8.5$ & $65.2 \pm 9.5$ & 0.375 \\
Female & $82(54.7 \%)$ & $18(51.4 \%)$ & 0.851 \\
Body mass index $\left[\mathrm{kg} / \mathrm{m}^{2}\right]$ & $30.7 \pm 5.3$ & $29.9 \pm 4.6$ & 0.448 \\
Waist to hip ratio & $0.97 \pm 0.09$ & $0.96 \pm 0.09$ & 0.604 \\
Waist circumference [cm] & $105.2 \pm 13.3$ & $105.4 \pm 13.3$ & 0.927 \\
Systolic blood pressure $[\mathrm{mm} \mathrm{Hg]}$ & $143.3 \pm 19.6$ & $139.6 \pm 17.3$ & 0.306 \\
Diastolic blood pressure $[\mathrm{mm} \mathrm{Hg]}$ & $80.2 \pm 11.8$ & $78.3 \pm 13.2$ & 0.410 \\
Duration of diabetes [years] & $9(4 ; 15)$ & $6(3 ; 19)$ & 0.607 \\
History of smoking & $85(56.7 \%)$ & $22(62.9 \%)$ & 0.671 \\
Current smoking & $15(10 \%)$ & $4(11.8 \%)$ & 0.757 \\
Dyslipidemia & $127(84.7 \%)$ & $27(77.1 \%)$ & 0.316 \\
Hypertension & $134(89.3 \%)$ & $32(91.4 \%)$ & 1.000 \\
Metabolic syndrome & $129(86 \%)$ & $30(85.7 \%)$ & 1.000 \\
Coronary artery disease & $90(60 \%)$ & $22(62.9 \%)$ & 0.849 \\
Prior myocardial infarction & $47(31.3 \%)$ & $12(34.3 \%)$ & 0.841 \\
Prior stroke & $12(8 \%)$ & $1(2.9 \%)$ & 0.468 \\
Prior TIA & $7(4.7 \%)$ & $1(2.9 \%)$ & 1.000 \\
Heart failure & $60(40.3 \%)$ & $17(48.6 \%)$ & 0.447 \\
\hline
\end{tabular}

LPR — low platelet reactivity; HPR — high platelet reactivity; TIA — transient ischemic attack

Table 4. Concurrent medications.

\begin{tabular}{lccc}
\hline Characteristics & LPR $(\mathbf{n}=\mathbf{1 5 0 )}$ & HPR $(\mathbf{n}=35)$ & P \\
\hline Beta-blockers & $104(69.3 \%)$ & $26(74.3 \%)$ & 0.683 \\
ACE inhibitors & $99(66 \%)$ & $19(54.3 \%)$ & 0.241 \\
Angiotensin receptor blocker & $25(16.7 \%)$ & $9(25.7 \%)$ & 0.229 \\
Aldosterone antagonists & $11(7.3 \%)$ & $2(5.7 \%)$ & 1.000 \\
Loop diuretics & $25(16.7 \%)$ & $4(11.4 \%)$ & 0.607 \\
Thiazide diuretics & $50(33.3 \%)$ & $13(37.1 \%)$ & 0.695 \\
Statins & $113(75.3 \%)$ & $20(57.1 \%)$ & 0.038 \\
Fibrates & $21(14 \%)$ & $4(11.4 \%)$ & 0.791 \\
Calcium channel blockers & $49(32.7 \%)$ & $16(45.7 \%)$ & 0.170 \\
Nitrates & $10(6.7 \%)$ & $1(2.9 \%)$ & 0.693 \\
Proton pump inhibitor & $37(24.6 \%)$ & $9(25.7 \%)$ & 0.897 \\
Metformin & $93(62 \%)$ & $25(71.4 \%)$ & 0.334 \\
Sulphonylurea derivatives & $72(48 \%)$ & $13(37.1 \%)$ & 0.265 \\
Alpha-glucosidase inhibitors & $11(7.3 \%)$ & $1(2.9 \%)$ & 0.468 \\
Insulin & $48(32 \%)$ & $12(34.3 \%)$ & 0.842 \\
\hline
\end{tabular}

LPR — low platelet reactivity; HPR — high platelet reactivity; ACE — angiotensin-converting enzyme

TNF- $\alpha$ concentrations, at marginal significance level ( 2.15 vs. $1.74 \mathrm{pg} / \mathrm{mL}, \mathrm{p}=0.052)$. HPR group in comparison to LPR group had significantly higher level of S-TxB2 (median $0.16 \mathrm{ng} / \mathrm{mL}$ [25; 75 percentiles - $0.07 ; 0.47]$ vs. $1.62 \mathrm{ng} / \mathrm{mL}$ [25; 75 percentiles $0.37 ; 4.28], \mathrm{p}<0.001)$. Concomitant medications were comparable in both groups, with the excep- tion of statin usage. Patients with adequate platelet response to ASA were taking statins more frequently than HPR patients - $113(75.3 \%)$ vs. $20(57.1 \%) ; p=0.038$. No other significant differences were observed between two investigated groups. In the simple logistic regression model, only two parameters were found to be predictive of HPR: 
Table 5. Baseline biochemistry and hematology.

\begin{tabular}{|c|c|c|c|}
\hline Characteristics & $\operatorname{LPR}(n=150)$ & HPR $(n=35)$ & $\mathbf{P}$ \\
\hline Hemoglobin $[\mathrm{g} / \mathrm{dL}]$ & $13.8 \pm 1.2$ & $14.1 \pm 1.9$ & 0.296 \\
\hline Hematocrit [\%] & $41.1 \pm 3.3$ & $41.9 \pm 5.1$ & 0.435 \\
\hline Leukocytes $\left[10^{3} / \mathrm{mm}^{3}\right]$ & $7.0 \pm 2.1$ & $7.1 \pm 1.6$ & 0.984 \\
\hline Platelet count $\left[10^{3} / \mathrm{mm}^{3}\right]$ & $230.9 \pm 59.6$ & $229.8 \pm 60.5$ & 0.919 \\
\hline Mean platelet volume [fL] & $9.8 \pm 1.2$ & $9.8 \pm 1.2$ & 0.923 \\
\hline Fasting glucose [mg/dL] & $127(110 ; 151)$ & $133(113 ; 156)$ & 0.318 \\
\hline Urea [mg/dL] & $42.8 \pm 15.1$ & $41.9 \pm 16.9$ & 0.756 \\
\hline Creatinine [mg/dL] & $1.01 \pm 0.32$ & $1.03 \pm 0.30$ & 0.703 \\
\hline eGFR [mL/min/1.73] & $71.8 \pm 21.5$ & $67.9 \pm 18.5$ & 0.329 \\
\hline Uric acid [mg/dL] & $5.7 \pm 1.4$ & $5.7 \pm 1.5$ & 0.759 \\
\hline Total cholesterol [mg/dL] & $163.7 \pm 34.5$ & $169.8 \pm 40.2$ & 0.361 \\
\hline Triglycerides [mg/dL] & $118(87 ; 160)$ & $145(105 ; 180)$ & 0.041 \\
\hline HDL-cholesterol [mg/dL] & $49.3 \pm 14$ & $46.3 \pm 14.1$ & 0.259 \\
\hline LDL-cholesterol [mg/dL] & $86 \pm 29.6$ & $93.6 \pm 35.6$ & 0.191 \\
\hline $\mathrm{HbA}_{1 \mathrm{c}}[\%]$ & $7.1 \pm 1.2$ & $7.2 \pm 1.2$ & 0.718 \\
\hline VerifyNow [ARU] & $452 \pm 45$ & $597 \pm 39$ & $<0.001$ \\
\hline Serum TxB2 [ng/mL] & $0.16(0.12 ; 0.47)$ & $1.62(0.37 ; 4.28)$ & $<0.001$ \\
\hline TNF- $\alpha[\mathrm{pg} / \mathrm{mL}]$ & $1.744(1.217 ; 2.423)$ & $2.148(1.521 ; 2.696)$ & 0.052 \\
\hline hsCRP [mg/L] & $2.8(1.5 ; 5.4)$ & $2.3(1.3 ; 4.0)$ & 0.405 \\
\hline
\end{tabular}

LPR — low platelet reactivity; HPR — high platelet reactivity; $\mathrm{HbA}_{1 \mathrm{c}}$ - glycosylated hemoglobin; $\mathrm{HDL}$ - high density lipoprotein; LDL - low density lipoprotein; eGFR - estimated glomerular filtration rate; TNF- $\alpha$ - tumor necrosis factor-alpha, hsCRP — high-sensitivity C-reactive protein

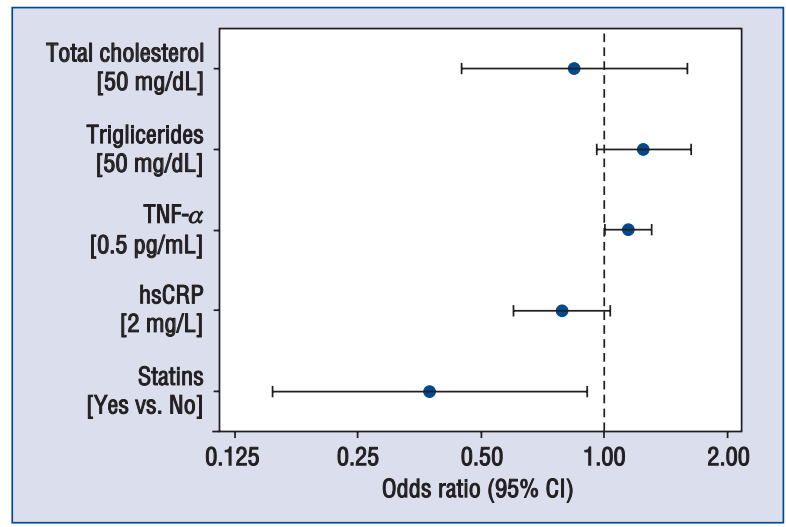

Figure 1. Results of the multivariate logistic regression model; TNF- $\alpha$ - tumor necrosis factor-alpha; hsCRP high-sensitivity $\mathrm{C}$-reactive protein; $\mathrm{Cl}$ - confidence interval.

current statin therapy $(\mathrm{p}=0.034)$ and $\mathrm{TNF}-\alpha$ concentration $(\mathrm{p}=0.040)$. Variables with $\mathrm{p}<0.10$ together with parameters affected by statin therapy were entered into the multivariate analysis to determine their independent association with ASA low-responsiveness. Variables associated with HPR in the multivariate analysis were: TNF- $\alpha$ concentrations (for each $1.0 \mathrm{pg} / \mathrm{mL}$ : OR 1.3; 95\% CI 1.00-1.72;

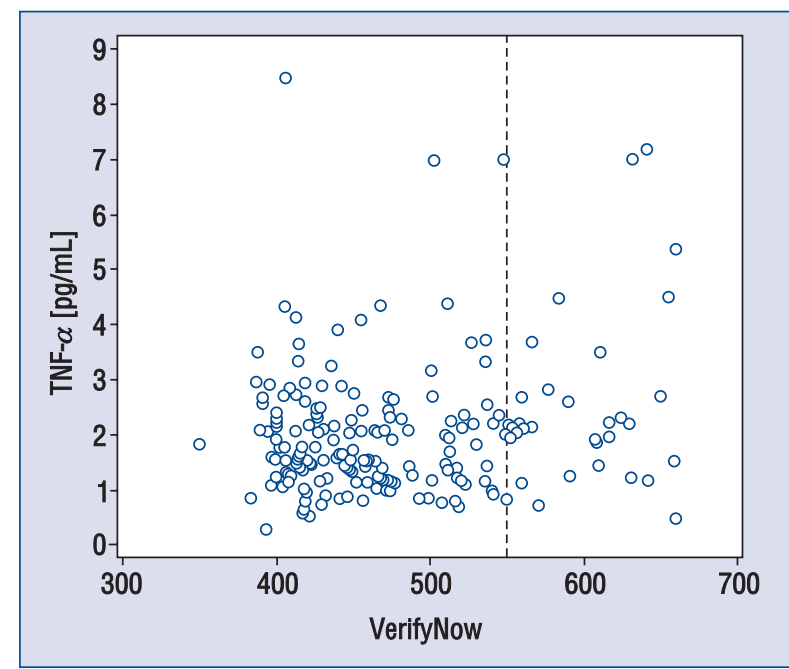

Figure 2. Scatterplot of tumor necrosis factor-alpha (TNF- $\alpha$ ) concentrations vs. ASA reaction units values by VerifyNow ${ }^{\circledR}$ Aspirin Assay.

$\mathrm{p}=0.046$; for each $0.5 \mathrm{pg} / \mathrm{mL}$ : OR $1.147 ; 95 \% \mathrm{CI}$ $1.00-1.31 ; \mathrm{p}=0.046)$ and statin therapy (OR 0.375; $95 \%$ CI $0.15-0.91 ; p=0.030$ ) (Fig. 1). The distribution of TNF- $\alpha$ concentrations in relation to ARU values is shown in Figure 2. In additional analysis 
neither the type of statin used, nor the dose of statin were found to be predictive of HPR in diabetic population (OR 1.007; 95\% CI 0.280-3.63; $\mathrm{p}=0.992)$.

\section{Discussion}

There are relatively few publications, which focus on identifying risk factors of HPR in patients with T2DM on ASA therapy. In patients with diabetes, the prevalence of residual platelet reactivity despite ASA therapy has been estimated by others to be as low as $2.8 \%$ up to $22 \%$, which corresponds to the prevalence of increased platelet reactivity on ASA therapy observed in this study population $[4,6,7,10]$. In comparison to most previous studies, all of the patients included in our study were taking an uniform ASA dose of $75 \mathrm{mg}$ as in study presented by Mortensen et al. [6]. VerifyNow ${ }^{\circledR}$ Aspirin Assay is considered to be an optimal method to detect ASA effect on platelets as it demonstrates a very high sensitivity to ASA effect [11]. Thus, it is not surprising that in our study we observed statistically higher levels of S-TxB2 in the group with HPR in comparison to the LPR group (Table 5), which is in accordance to that previously reported [12].

The strengths of the present study are inclusion of a study population of only diabetic patients with established coronary artery disease $(\mathrm{CAD})$ or with multiple CAD risk factors and assessment of compliance. Of the ASA low-responsiveness risk factors that had been reported previously, only triglyceride concentration differed significantly between the HPR and LPR groups when investigated in our study population. However, in the multivariate analysis, triglyceride concentration was not predictive of HPR. No significant differences between the HPR and LPR groups were found with respect to glycemic control or cholesterol concentration.

In the current study, only two variables (i.e., TNF- $\alpha$ concentration and statin therapy) were found to be independent predictors of HPR by the multivariate analysis. To our knowledge, this is the first study to demonstrate a correlation between TNF- $\alpha$ concentrations and increased platelet reactivity on ASA therapy in an exclusively diabetic population. Although the association between inflammation and enhanced platelet reactivity has long been recognized, there are only a few reports of increased CRP and interleukin- 6 concentrations in patients with high platelet reactivity on ASA therapy [13]. Possible mechanisms linking inflammation with increased platelet reactivity on antiplatelet therapy include: increased platelet turnover, endothelial dysfunction, enhanced expression of cyclooxygenase isoenzyme 2 , non-platelet sites of thromboxane $\mathrm{A}_{2}$ synthesis, and increased levels of various prothrombotic clotting factors with platelet-activating properties $[3,14]$. However, only a few studies that examined the effects of statins on TNF- $\alpha$ demonstrate that statins either have no effect on or reduce circulating TNF- $\alpha$ concentrations [15-17]. We assume that the ambiguous effect of statins on TNF- $\alpha$ concentration could in part explain the observed association with TNF- $\alpha$, but not with CRP level. Thus, subclinical systemic inflammation might, therefore, be the key link between T2DM and high platelet reactivity on ASA therapy.

Our study is also the first one to demonstrate a possible beneficial influence of statin therapy on platelet reactivity in a diabetic population on longterm ASA treatment. To date, only a few studies have shown a positive effect of statins on platelet responsiveness to ASA [18-20]. In the study by Tirnaksiz et al. [18], high-dose atorvastatin therapy resulted in improvement of ASA responsiveness in 13 of 20 patients with stable CAD, as assessed with a Platelet Function Analyzer (PFA-100 ${ }^{\circledR}$ ). In another study, a combination of atorvastatin and ASA in patients with myocardial infarction reduced thromboxane $\mathrm{A}_{2}$ synthesis and platelet aggregation measured by light transmission aggregometry (LTA) when compared to patients receiving ASA [18]. In our study, concomitant statin therapy was predictive of low platelet reactivity measured with VerifyNow ${ }^{\circledR}$, irrespective of type and dose of statin, or cholesterol and triglyceride levels.

Our study provides indirect evidence that the beneficial effect of statins on platelet activity may be related to their non-lipid-mediated, pleiotropic mechanisms of action. This might have been partly related to decreased platelet reactivity in patients receiving statin therapy.

In our study in patients with T2DM, platelet reactivity on ASA therapy measured with VerifyNow ${ }^{\oplus}$ was associated with TNF- $\alpha$ concentrations and statin therapy. This implies inflammation having a role in the development of ASA resistance in T2DM, as well as a protective effect of statins related to their lipid-independent mechanisms of action.

\section{Limitations of the study}

Our study has two important limitations. First, we assessed platelet reactivity on ASA therapy with use of a point-of-care test - VerifyNow ${ }^{\circledR}$ Aspirin Assay - instead of the "gold standard" LTA [11]. However, the mode of action of the VerifyNow ${ }^{\circledR}$ Aspirin Assay is similar to LTA, and the VerifyNow ${ }^{\circledR}$ system is one of the most widely used methods for assessing platelet function. In addition, according 
to previous reports, the VerifyNow ${ }^{\oplus}$ method demonstrates the highest correlation with arachidonic acid-induced LTA in comparison to other platelet function tests [11]. Secondly, a prospective, randomized experimental study would be more beneficial for directly demonstrating any beneficial influence of statin therapy on platelet reactivity. However, the aim of our current study was to identify potential independent risk factors of increased platelet reactivity in a population of T2DM patients for future investigation. Pretreatment measurements could not be conducted because all patients included in this study had diagnosed CAD or multiple risk factors for $\mathrm{CAD}$ and therefore were on ASA therapy at the time of enrollment.

\section{Acknowledgments}

The authors alone are responsible for the content and writing of this paper. The AVOCADO study was supported financially as part of the research grant from the Polish Pharmaceutical Company ADAMED for a Young Scientist 2007 Award [grant number: 1WR DAR1/2007].

Conflict of interest: none declared

\section{References}

1. Ryden L, Standl E, Bartnik M et al. Guidelines on diabetes, prediabetes, and cardiovascular diseases: executive summary. The Task Force on Diabetes and Cardiovascular Diseases of the European Society of Cardiology (ESC) and of the European Association for the Study of Diabetes (EASD). Eur Heart J, 2007; 28: 88-136.

2. Cohen HW, Crandall JP, Hailpern SM, Billett HH. Aspirin resistance associated with $\mathrm{HbA1c}$ and obesity in diabetic patients. J Diabetes Complications, 2008; 22: 224-228.

3. Singla MK, Lahiri P, Mukhopadhyay P, Pandit K, Chaudhuri U, Chowdhury S. A study of aspirin resistance in type 2 diabetes. J Indian Med Assoc, 2008; 106: 720, 722-723, 740.

4. Yassine HN, Davis-Gorman G, Stump CS, Thomson SS, Peterson J, McDonagh PF. Clinical determinants of aspirin resistance in diabetes. Diabetes Res Clin Pract, 2010; 90: 19-21.

5. Ertugrul DT, Tutal E, Yildiz M et al. Aspirin resistance is associated with glycemic control, the dose of aspirin, and obesity in type 2 diabetes mellitus. J Clin Endocrinol Metab, 2010; 95: 2897-2901.

6. Mortensen SB, Larsen SB, Grove EL, Kristensen SD, Hvas AM. Reduced platelet response to aspirin in patients with coronary artery disease and type 2 diabetes mellitus. Thromb Res, 2010; 126: 318-322.

7. DiChiara J, Bliden KP, Tantry US et al. The effect of aspirin dosing on platelet function in diabetic and nondiabetic patients:
An analysis from the aspirin-induced platelet effect (ASPECT) study. Diabetes, 2007; 56: 3014-3019.

8. Dichiara J, Bliden KP, Tantry US et al. Platelet function measured by VerifyNow identifies generalized high platelet reactivity in aspirin treated patients. Platelets, 2007; 18: 414-423.

9. Postula M, Kaplon-Cieslicka A, Rosiak M et al. Genetic determinants of platelet reactivity during acetylsalicylic acid therapy in diabetic patients: Evaluation of 27 polymorphisms within candidate genes. J Thromb Haemost, 2011; 9: 2291-2301.

10. Fateh-Moghadam S, Plockinger U, Cabeza N et al. Prevalence of aspirin resistance in patients with type 2 diabetes. Acta Diabetol, 2005; 42: 99-103.

11. Blais N, Pharand C, Lordkipanidze M, Sia YK, Merhi Y, Diodati JG. Response to aspirin in healthy individuals. Cross-comparison of light transmission aggregometry, VerifyNow system, platelet count drop, thromboelastography (TEG) and urinary 11-dehydrothromboxane B(2). Thromb Haemost, 2009; 102: 404-411.

12. Grove EL, Hvas AM, Johnsen HL et al. A comparison of platelet function tests and thromboxane metabolites to evaluate aspirin response in healthy individuals and patients with coronary artery disease. Thromb Haemost, 2010; 103: 1245-1253.

13. Englyst NA, Horsfield G, Kwan J, Byrne CD. Aspirin resistance is more common in lacunar strokes than embolic strokes and is related to stroke severity. J Cereb Blood Flow Metab, 2008; 28: 1196-1203.

14. Shetty GK, Economides PA, Horton ES, Mantzoros CS, Veves A. Circulating adiponectin and resistin levels in relation to metabolic factors, inflammatory markers, and vascular reactivity in diabetic patients and subjects at risk for diabetes. Diabetes Care, 2004; 27: 2450-2457.

15. Bayes B, Granada ML, Lauzurica R et al. Effect of low doses of atorvastatin on adiponectin, glucose homeostasis, and clinical inflammatory markers in kidney transplant recipients. Transplant Proc, 2005; 37: 3808-3812.

16. Ando H, Sugimoto K, Yanagihara $\mathrm{H}$ et al. Effects of atorvastatin and pravastatin on glucose tolerance, adipokine levels and inflammatory markers in hypercholesterolaemic patients. Clin Exp Pharmacol Physiol, 2008; 35: 1012-1017.

17. Santos MT, Fuset MP, Ruano M, Moscardo A, Valles J. Effect of atorvastatin on platelet thromboxane $\mathrm{A}(2)$ synthesis in aspirin-treated patients with acute myocardial infarction. Am J Cardiol, 2009; 104: 1618-1623.

18. Tirnaksiz E, Pamukcu B, Oflaz H, Nisanci Y. Effect of high dose statin therapy on platelet function; statins reduce aspirin-resistant platelet aggregation in patients with coronary heart disease. J Thromb Thrombolysis, 2009; 27: 24-28.

19. Eikelboom JW, Hankey GJ, Thom J et al. Incomplete inhibition of thromboxane biosynthesis by acetylsalicylic acid: Determinants and effect on cardiovascular risk. Circulation, 2008; 118: 1705-1712.

20. Undas A, Siudak Z, Brummel-Ziedins K, Mann KG, Tracz W. Prothrombinase formation at the site of microvascular injury and aspirin resistance: The effect of simvastatin. Thromb Res, 2010; 125: 283-285. 